\title{
The Roaring Hammock
}

\author{
Sabiha Ghellal ${ }^{1}$, Nick Mussin ${ }^{1}$, Ann Morrison $^{2}$ \\ Mobile Media, Stuttgart Media University ${ }^{1}$ \\ Architecture, Design and Media Technology University of Aalborg ${ }^{2}$
}

\begin{abstract}
The Roaring Hammock is an experimental transmedia installation aimed at exploring holistic experiences through an interactive artefact and its surroundings. This interactive hammock uses microcontrollers, sensors, audio and visual feedback to create an interactive holistic experience. Participants can playfully influence the hammock by rocking or swinging and become part of the installation. With the Roaring Hammock we investigate speculation by inviting participants to actively explore (through their own embodied actions) to find out how the hammock works without instruction.
\end{abstract}

\section{Introduction}

Sensor and microcontroller technologies allow for novel more embedded holistic experiences. For the Roaring Hammock (figure 1) we informed our design by combining the HCI theories of Experience Design (Gaver et al. 2003, Forlizzi et al. 2004 \& Hassenzahl et al. 2013), Speculative Play (Morrison et al. 2011) and Performativity (Jacucci et al. 2009) with microcontroller and sensor based technologies in order to allow for novel embedded experiences. With the Roaring Hammock, we extend the physicality of rocking in a hammock with interactive content presentation using ambiguity (Gaver et al. 2003). Within the HCI community ambiguity is described as a resource to build one's own narratives and meaning (Vyas et al. 2006). Here, experience is understood as an act of appropriation made possible by artefacts, in our case the interactive hammock. Since we wanted to instil a feeling of investigation and speculation while playing with the hammock we further borrowed from the theory of Speculative Play (Morrison et al. 2011) where participants are invited to actively figure out how the hammock works with a deliberate lack of instruction. For the Roaring Hammock we built upon the notion of experience-oriented or Experience Design (Gaver et al. 2003, Forlizzi et al. 2004 \& Hassenzahl et al. 2013) by focusing on the individual hedonic qualities when experiencing this audio-visual installation. The goal of this installation is to investigate and deepen knowledge on how to design fulfilling, meaningful and engaging embedded experiences. 


\section{The Roaring Hammock}

The Roaring Hammock (figure 1) is reminiscent of the "Roaring Twenties". It uses sensors, audio and visual feedback to create an interactive holistic experience while lying in a hammock. Participants can playfully influence the hammock by rocking or swinging. For the participant the interactive challenge with this work is to move the hammock in a rhythm that will play the music at a pleasing speed. The participant becomes part of the installation via their interactive performativity (Jacucci et al. 2009), that is, s/he can directly influence the musical experience by "dancing" in the hammock. Our goal was to create a worthwhile experience that embodies swing music and dancing as a new form of engagement with material. The defining visual metaphor of the Roaring Hammock is a gramophone, see figure 1. The hammock starts playing twenties swing music when participants "fall into" the hammock and begin swinging. Their movement propels a vinyl disc that is projected on a canvas above the hammock. As the participants start swinging, the vinyl disc starts turning on the canvas and music begins to play. The more and the stronger participants swing, the faster the vinyl disc spins and the faster and higher-pitched the music gets. This behaviour is analogous to a real vinyl disc player, where the rotation rate determines playback speed and tone pitch. A scale and a slider provide feedback on the canvas, indicate current playback speed and support this visualisation. The gramophone metaphor illustrates the connection between the function, interaction, visual presentation and the musical content and speed for a coherent and comprehensible composition during play.

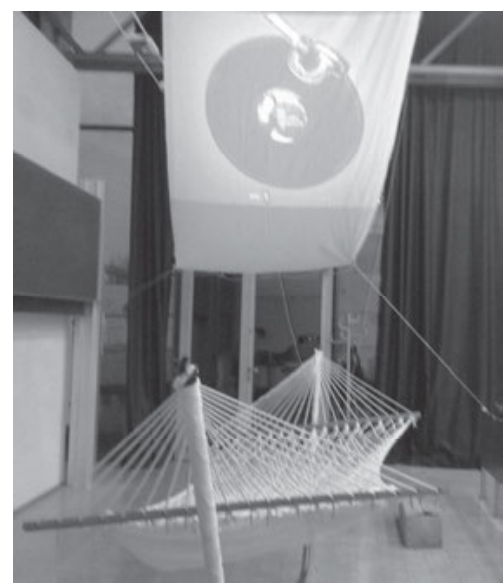

Figure 1: The Roaring Hammock

\section{Installation Set-Up}

The basic setup (figure 2) consists of a commonly available net hammock, equipped with sensors to enable participant interaction with the installation, as well as loudspeakers embroidered into the hammock to render the audio content. As a projection area for the 
visualisation we place a fabric canvas above the hammock. For facilitating reading and processing of sensor data, we install an open source microcontroller platform. To obtain motion data, we place a small breakout board on one end of the hammock containing both an accelerometer to measure acceleration and a gyroscope to measure orientation. The software controlling the hammock installation is spread across two computers and the microcontroller. A desktop computer is used to render the visualisation projected on the canvas along with the music and soundscape installation. A second microcontroller is used to receive the sensor data from a microcontroller.

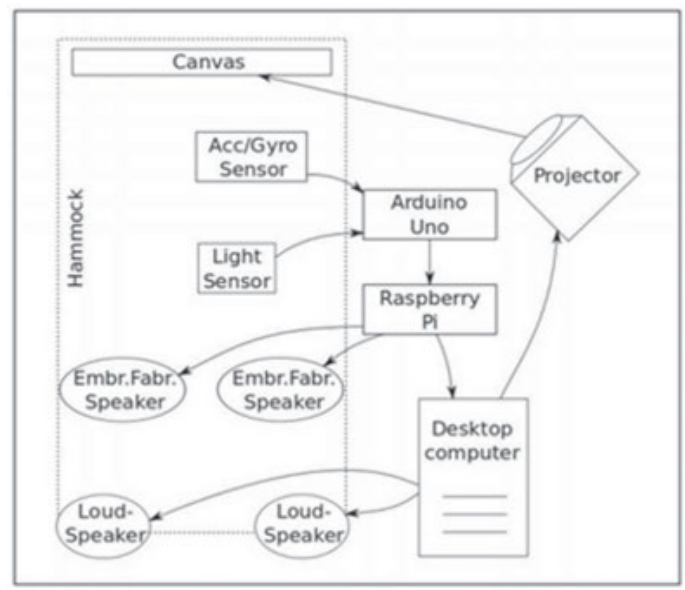

Figure 2: Installation Set-Up

\section{Experience Design}

For designing the Roaring Hammock we employed the game design theory of a magic circle. Zimmerman et al. (2003) explains that playing a game means to enter into a magic circle. In our installation "falling" into the hammock should feel like entering such a magical world that is based on a holistic all-encompassing interactive experience. This holistic experience shapes swing music into an interactive audio-visual endeavour and allows the participant to become part of an installation through actively 'performing' while lying in the hammock. However, in order to design for such a holistic experience we found it helpful to separate materials that shape an experience into functionality, content, presentation and interaction (Hassenzahl 2010). We identified the presentation as the visual feedback on the canvas above the hammock; see figure 1 . The content was designed using visuals inspired by the "Roaring Twenties" featuring swing music and a gramophone with a "beat per minute feedback"- widget, see figure 1. The functionality, lying in the hammock or rocking the hammock, was used to direct the interactive experience of influencing the audio-visual content based on movement of the participant using sensor data. 


\section{Conclusion}

Sensor and microcontroller technologies allow for novel experiences that extend artefacts into technology driven experiences and bear the potential of redefining the utility of everyday materials such as a commonly available hammock. With the installation the Roaring Hammock we invite visitors to experience a novel audio-visual installation by playfully interacting with our hammock. How participants move in the hammock defines the type of experience they have. We invite participants to explore this through their own initiative and embodied activities.

\section{Acknowledgements}

This work was supported by REMEX, a Stuttgart Media University research group and was partially supported by the EU funded project CultAR (FP7-ICT-2011-9 601139).

\section{References}

Forlizzi, J. \& Battarbee, K. (2004). Understanding experience in interactive systems. In Proc. DIS 2004, ACM Press, pp. 261-268.

Gaver, W., Beaver, J. \& Benford, S. (2003). Ambiguity as a resource for design. In Proc. CHI 2003, ACM Press, pp. 233-240.

Hassenzahl, M. (2010). Experience design: Technology for all the right reasons. Synthesis Lectures on Human-Centered Informatics, 3 (1) pp. 1-95.

Hassenzahl, M., Eckoldt, K., Diefenbach, S., Laschke, M., Lenz, E. \& Kim, J. (2013). Designing moments of meaning and pleasure. Experience design and happiness. International Journal of Design 7, (3) pp. 21-31.

Jacucci, G., Spagnolli, A., Chalambalakis, A., Morrison, A., Liikkanen, L., Roveda, S. \& Bertoncini, M. (2009). Bodily explorations in space. In Proc. INTERACT 2009, Springer-Verlag, pp. 62-75.

Morrison, A., Viller, S. \& Mitchell, P. (2011) Building sensitising terms to understand free-play in open-ended interactive art environments. In Proc. SIGCHI 2011, ACM Press, pp. 2335-2344.

Salen, K. \& Zimmerman E. (2003). Rules of Play: Game Design Fundamentals, The MIT Press.

Vyas, D. \& Van Der Veer, G. C. (2006). Experience as meaning. In Proc. 13th European conference on Cognitive ergonomics, ACM Press, pp. 81-91.

\section{Contact}

Sabiha Ghellal

Mobile Media, Stuttgart Media University

DE 70569 Stuttgart, Nobelstrasse 10

Email: ghellal@hdm-stuttgart.de

Web: www.sabiha-ghellal.com 